\title{
Lo esencial antes de lo remoto: narrativas pedagógicas en tiempos de pandemia
}

\author{
The essentials before the remote: \\ Pedagogical narratives in times of pandemic
}

Cindy Julieth Martínez Ruiz

\begin{abstract}
Para citar este artículo: Martínez, C. J. (2020). Lo esencial antes de lo remoto: narrativas pedagógicas en tiempos de pandemia. Infancias Imágenes, 19(2), 147-150
\end{abstract}

\section{Resumen}

¡Qué bueno es enseñar a la par de la horizontalidad! Desde el ciclo de talleres "Un encuentro con maestros: compartir de voces, saberes y experiencias" emprendimos un viaje al acceso, disfrute y descentralización del conocimiento, siendo las y los estudiantes inscritos durante el periodo intersemestral a la asignatura Práctica en Responsabilidad Social de la Corporación Universitaria Minuto de Dios (sede principal) quienes capitanearon la nave y yo fui su pasajera, corresponsal y consejera.

Palabras clave: práctica en responsabilidad social, quehacer pedagógico y transversalidad educativa.

1 Docente del Centro de Educación para el Desarrollo, Corporación Universitaria Minuto de Dios. Maestrante de Infancia y Cultura, Universidad Distrital Francisco José de Caldas. Especialista en Estudios Feministas y de Género, Universidad Nacional de Colombia. Licenciada en Educación Infantil, Universidad Pedagógica Nacional. Correo electrónico: cindy.martinez-r@uniminuto.edu.co 
Empieza el checklist: lista de asistencia, lecturas citadas formato APA en un syllabus, preparación del día, punto 1, 2, 3..., material pedagógico, marcadores de tablero, papel craft ¡no puede faltar!, presentación en PowerPoint. Ah... Claro, hay que pensar en una misma; se añade entonces la botella de agua que refresca olas de palabras y ahora, de un momento a otro, estos elementos conjugan algo que hemos denominado preparar clase o, mejor, prepararse para clase. Nada nos dice que estos elementos van a funcionar, bien o mal todas y todos los docentes puntuamos a nuestra manera un checklist mucho más extenso. Pero, ¿qué efectividad tiene?, ¿qué narrativas acompañan estos materiales?

El ingreso al aula no es menos estructurado. SiIlas azules dispuestas en cuadrículas, muros color naranja y escasa iluminación, cuerpos que ingresan 1, 2, 20, 35 .. jes el límite!, ojos expectantes y el efecto silente constante. La voz nos sitúa en un lugar jerárquico. No hace mucho escuché afirmar que: "quien controla las palabras, controla la realidad". Y sí, muchas y muchos enaltecen esta oportunidad como culmen de toda preparación, hablar desde un lugar ajeno y sin interlocución.

Mi cuerpo ha estado allí, ha frecuentado estos dos lugares; pero he de identificarme con aquel que en años se multiplica, donde mi cuerpo se ha acoplado al caer de las piernas y los pies en punta rosando el piso, las sillas también tienen un estándar; y bueno... tampoco fui hecha a esa medida. Allí mismo donde las manos se aceleran a escribir o en ocasiones son un apoyo fundamental para no abandonar el mentón y el peso de la cabeza que va a caer. Sin lugar a duda, he acariciado con admiración las palabras que pintan de otro color estos lugares sombríos Ilamados aulas, pero un mayor número de veces el silencio que estimula el eco ha desbordado con molestia la creación de mis gestos, que solo esperan salir lo más pronto posible de estos no-lugares.

Ahora me encuentro "al frente" de un grupo, son mucho más grandes en estatura que yo por supuesto; algunos sobrepasan mi edad, sus profesiones no son para mí una etiqueta evidente, por el momento son cuerpos que gozan de reposo en una silla y no soporto verles tan cuadriculados, sus ojos están agotados ¡trabajan! No preparo presentación PowerPoint, no me afana la lista de asistencia. Y, entonces, recuerdo las palabras que daban inicio a esa aventura, son cortas y no tienen un sentido claro: “¿Me ayudan con las sillas?”. Un movimiento circular con mi dedo índice y el brazo estirado dejaban en un chasquear de dedos el centro del aula lista para empezar.

Las sillas azules eran solamente eso, objetos prácticos para dejar las maletas, celulares y todo aquello que estorbaba. Una y otra vez esta experiencia se repetía y hacía que se perdiera, que no se notara y no brillara esa jerárquica voz; éramos muchas voces, cuerpos en movimiento sin aparente orden, pero con un evidente sentido colectivo. Afortunadamente nos movíamos de espacio y emergían otros encuentros; el aula por supuesto era desbordada por nuestro potencial; las organizaciones sociales o comunitarias de Bogotá nos esperaban.

Caminar era el sinónimo de compartir, dejarse afectar un poco, ser sensible o valorar eran sinónimos de esta experiencia ¡Lo esencial! En voz de las y los estudiantes. Niñas y niños salían corriendo, otros se quedaban quietos y esperaban, pero al unísono replicaban "¡Llegaron los profes!". Así les recibían, con un cargamento de expectativas, pero... no demoraba el efecto espejo hacer de las suyas. Niñas y niños en sillas y mesas pequeñas, espacios estrechos, paredes blancas, el grito se asomaba y estallaba, hay un silencio... Un déjà vu ¡Lo hemos vivido!

La narrativa da vueltas, se transforman los lugares de enunciación. Las y los estudiantes toman en sus manos el checklist. ¿Qué prepararán? ¿Cuáles palabras las y los acompañarán? ¿Qué les incomodará? ¿Será el margen de inequidad? Al lector de estas palabras le he de decir que son respuestas que no obtengo con facilidad. Por ello, me es necesario ir más allá, al meollo del asunto, donde sus cuerpos transitan desde la obligatoriedad de una asignatura transversal (Práctica en Responsabilidad Social)1 , al encuentro con la "realidad", esa

1 Para Uniminuto la responsabilidad social es "i) un supuesto ético y político, ii) un pilar del Modelo Educativo, iii) un área de formación del Modelo Curricular y iv) un curso obligatorio en los planes académicos de los estudiantes de todos los programas tecnológicos y profesionales" Corporación Universitaria Minuto de Dios (2018; p. 89) 
que parece lejana o exótica, esa de la que poco se habla y mucho se señala.

Y ahora, ¿leer la realidad desde la virtualidad? Estos meses que parecen años al compás de los teclados, micrófonos silenciados, enlaces de conexión enviados y ecos como invitados hacen que la antesala de rememorar el aula no nos sea ajena. Acaso, ¿de qué manera dejábamos habitar la palabra y el contacto físico que tanto extrañamos? ¿De qué manera se ha dado paso al borrón y cuenta nueva de los contenidos programáticos? ¿En qué momento nos hemos dejado afectar para movilizar-nos? ¡Claro, es un reto! El espacio físico convocaba la palabra y acción, pero la virtualidad nos guio al margen de nuestra imaginación.

Así, en respuesta a esta realidad que nos apuró y, ¿por qué no decirlo?, nos forzó con el término "reinventar" a camuflar la equidad, se presenta una oportunidad en articulación con la Cátedra Unesco en el Desarrollo del Niño y su ciclo de talleres desde la Universidad Distrital Francisco José de Caldas: "Un encuentro con maestros: compartir de voces, saberes y experiencias". Estudiantes que cursaron durante su periodo intersemestral la asignatura Práctica en Responsabilidad Social, sus micrófonos, voces y narrativas comenzaron a probar, entonar e intentar, para tripular la radio nave en frecuencia 90.4 fm, (programa Tripulantes).

Con tan solo un clic, el "tirín" de una solicitud aceptaba en Meet y una nave con sus capitanes y tripulantes, deambulamos en dimensiones no pensadas. Iniciamos por la tangibilidad de acceso a una educación pública y de calidad, nos dirigimos al planeta del hilar y explorar la voz como burla al eco abrumador. Disfrutamos del arte de escribir y saber preguntar, sin perder de vista la perspicacia de nuestra labor: co-construir posibles con, para y desde los diversos lugares de enunciación de niñas, niños y jóvenes.

La palabra aterrizó la necesidad de saber situar ética y políticamente nuestros privilegios. ¡Teníamos el acceso! Podíamos con un clic viajar y, entonces, ¿cómo difundir en equidad esta posibilidad? Como alternativa, la voz seguiría viajando, hasta Ilegar a lugares inhóspitos afirmando que no se trata de "dar voz a las y los sin voz". En su lugar, nos acogíamos a la imperiosa labor de "saber callar, el silencio aguardar y aprender a escuchar". Fuimos tripulantes, corresponsales y pasajeros, nos dejamos guiar del verbo soñar sonante de fronteras acabar y accionante de ondas radiales que entre el quehacer y las utopías tranversalizan el sentido de la pedagogía.

Es menester afirmar que ifue el momento de ellas y ellos, de las y los estudiantes! De clase en clase, el silente característico, el slash que acciona el micrófono rojo muy pocas veces desaparecía; éramos expectantes de otros posibles con un sin fin de historias por narrar. Pero, ¿saben? Era mi tiempo de escuchar, detenerme y disfrutar del hilar, una, otra y otra palabra más, de modular la voz y saber cuándo parar, de respirar profundo y detallar el aire de saber pronunciar: eco, pro-fe, ho-la, gra-ci-as-, de escribir y organizar historias en libertos con inicio y en suspensivo su final.

Fue grato distribuir tareas y en la balanza descubrir que, sin distinción, cualquier profesión tiene a su alcance el don de la imaginación. Fue nuestro momento de explorar. ¿Quién iba a pensar que con un clic a otra dimensión puedes ingresar? Con voz de tripulante, pasajera, corresponsal, qué fortuna es dejarse entre ondas llevar y en frecuencias activar, la magia colectiva del saber y saberse narrar.

Por consiguiente, si no es a través de la horizontalidad que emergen estas letras, sentires y disentires, ¿desde qué otros lugares podrían nacer olas de palabras? Si mi cuerpo no ha de producir saberes y performance cuantas veces le sea necesario, ¿cómo hablamos de deconstrucción? Si no sitúo mi historicidad y la afectación que ha tenido en mí, para estar donde estoy y pensar como pienso, no podría entonces pensar en las y los estudiantes que me permiten afectar sus realidades y que en estos momentos, gracias a las ondas y frecuencias radiales, se aventuran a lo remoto de la realidad, sin olvidar situar y situarse en lo esencial de una pedagogía al margen de la diversidad y alteridad en, para, desde y con niñas, niños y jóvenes en la ciudad de Bogotá. 


\section{Referencia}

Corporación Universitaria Minuto de Dios (2018).

Acuerdo 010 de enero de 2018.

http://www.uniminuto.edu/

documents/10798585/0/li-

neamientos+Generales+-+digital.pdf/

7c3779a0-fec2-4187-a085-e540216d6637

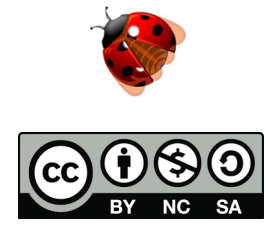

Esta obra está bajo licencia Creative Commons Atribución-NoComercial-Compartirlgual 4.0 Internacional https://creativecommons.org/licenses/by-nc-sa/4.0/deed.es

ISSN 1657-9089 • Vol. 19, no. 2 (julio-diciembre 2020). pp. 147-150 